\title{
Muted change in Atlantic overturning circulation over some glacial-aged Heinrich events
}

\author{
Jean Lynch-Stieglitz ${ }^{1 *}$, Matthew W. Schmidt ${ }^{2}$, L. Gene Henry ${ }^{1,7}$, William B. Curry ${ }^{3}$, Luke C. \\ Skinner ${ }^{4}$, Stefan Mulitza ${ }^{5}$, Rong Zhang ${ }^{6}$, Ping Chang ${ }^{2}$ \\ Submitted to Nature Geoscience 9/11/2012 \\ Revised for Nature Geoscience 11/11/2013 \\ Published: Nature Geoscience. 7: 144-150, 2014. doi: 10.1038/NGEO2045.
}

${ }^{1 *}$ School of Earth and Atmospheric Sciences, Georgia Institute of Technology, Atlanta, GA, 30307, USA jean@eas.gatech.edu.

${ }^{2}$ Department of Oceanography, Texas A\&M University, College Station, TX, 77843, USA.

${ }^{3}$ Woods Hole Oceanographic Institution, Woods Hole, MA 02543, USA.

${ }^{4}$ Godwin Laboratory for Palaeoclimate Research, Department of Earth Sciences, University of

Cambridge, Downing Street, Cambridge CB2 3EQ, UK.

${ }^{5}$ MARUM - Center for Marine Environmental Sciences, University of Bremen, Leobener

Strasse, D-28359 Bremen, Germany.

${ }^{6}$ NOAA/Geophysical Fluid Dynamics Laboratory, Princeton, NJ 08540, USA

$27{ }^{7}$ Now at Department of Earth and Environmental Sciences and Lamont-Doherty Earth

28 Observatory of Columbia University, Palisades, NY 10964 
Heinrich events - surges of icebergs into the North Atlantic Ocean - punctuated the last glacial period. The events are associated with millennial-scale cooling in the Northern Hemisphere. Freshwater from the melting icebergs is thought to have interrupted the Atlantic meridional overturning circulation, thus minimizing heat transport into the northern North Atlantic. The northward flow of warm water passes through the Florida Straits and is reflected in the distribution of seawater properties in this region. Here we investigate the northward flow through this region over the past 40,000 years using oxygen isotope measurements of benthic foraminifera from two cores on either side of the Florida Straits, which allow us to estimate water density, which is related to flow via the thermal wind relation. We infer a substantial reduction of flow during Heinrich Event 1 and the Heinrich-like Younger Dryas cooling, but little change during Heinrich Events 2 and 3, which occurred during an especially cold phase of the last glacial period. We speculate that because glacial circulation was already weakened before the onset of Heinrich Events 2 and 3, freshwater forcing had little additional effect. However, low-latitude climate perturbations were observed during all events. We therefore suggest these perturbations may not have been directly caused by changes in heat transport associated with Atlantic overturning circulation as commonly assumed.

Layers of ice rafted debris, Heinrich layers, appear periodically in the sediments of the North Atlantic that were laid down during the last glacial period. These layers are thought to represent surges of the large continental ice sheet that covered North America, discharging fresh water in the form of debris laden ice into the North Atlantic. The input of freshwater into the 
North Atlantic is postulated to have disrupted deep and bottom water formation, leading to a weaker Atlantic Meridional Overturning Circulation (AMOC).

The times surrounding the Heinrich Events (Heinrich Stadials) are clearly marked by extreme conditions in many records of oceanic and climatic change far from the North Atlantic.

These stadials are associated with drier than normal conditions in $\mathrm{China}^{1}$ and the $\mathrm{Sahel}^{2}$, and reduced ventilation of intermediate waters in the Arabian Sea ${ }^{3}$. Some Heinrich stadials are marked by warming of both the ocean and climate in the southern hemisphere ${ }^{4}$. It is thought that many of these far field effects of the ice discharges are transmitted by changes in the AMOC driven heat transport from the southern to the northern hemisphere, and the associated changes in atmospheric and oceanic circulation. If this were the case, we would expect to see evidence for changes in AMOC for each of the Heinrich Stadials.

\section{Expression of Heinrich Stadials in existing records of past ocean circulation}

Reconstructions of the water mass properties in the Atlantic during glacial times have yielded a picture of a nutrient poor water mass (Glacial North Atlantic Intermediate Water, GNAIW), overlying a nutrient rich water mass, presumably sourced from the south ${ }^{5}$.

Reconstructions of the density gradient in the upper ocean and model-data comparisons with deep water carbon isotope data suggest that if this configuration was associated with a shallower AMOC, this circulation was quite a bit weaker than the present day ${ }^{6-8}$. However, a recent model-data comparison suggests that sedimentary $\mathrm{Pa}$ and Th data are consistent with a strong, shallow AMOC ${ }^{9}$

It has been suggested that during Heinrich Stadials, this shallower AMOC was disrupted by freshwater input to the North Atlantic, leading to a virtual shutdown in the $\mathrm{AMOC}^{10}$. This 
idea was based on both ocean general circulation models which showed such a response to a large freshwater input, and data which suggested high nutrient values ${ }^{11}$ in deep waters around the time the most recent Heinrich layer (H1) was deposited. The idea of a weakened or non-existent overturning associated with $\mathrm{H} 1$ was bolstered by the discovery that the ratio of the particle reactive decay products of $\mathrm{U},{ }^{231} \mathrm{~Pa}$ and ${ }^{230} \mathrm{Th}$ are buried in the same ratio at which they are produced in the overlying water column in the open North Atlantic ${ }^{12}$.

Evidence for circulation changes associated with the Heinrich Events other than $\mathrm{H} 1$ has remained equivocal. The $\mathrm{Pa}$ and $\mathrm{Th}$ in deep Atlantic sediments do show a higher ratio during the stadials associated with $\mathrm{H} 2$ and $\mathrm{H} 3$, but these higher ratios are accompanied by evidence for an increase in opal flux to the seafloor, so may not necessarily indicate a circulation change ${ }^{13}$. Despite extensive efforts to reconstruct changes in water mass properties in the North Atlantic using carbon isotopic and trace metal measurements in the calcite tests of foraminifera, these records also do not show a clear picture of water mass changes for earlier Heinrich Events. This work is often hampered by poor time resolution and noisy data, perhaps due to productivity overprints $^{14}$. Some records suggest the presence of nutrient rich waters at intermediate $(<2 \mathrm{~km})$ depths during some of the Heinrich Stadials but not others ${ }^{15-20}$. However, the response is inconsistent among different locations in these upper water masses, suggesting that regional changes in productivity or circulation may have been responsible for these excursions towards more nutrient rich values. Deep water $(>2 \mathrm{~km})$ records show clear excursions towards a more nutrient-rich water mass during the stadials associated with $\mathrm{H} 4$ and $\mathrm{H} 5$ but not all records show changes around the time of $\mathrm{H} 2$ or $\mathrm{H} 3$ when deep water nutrient concentrations are already high (Supplemental Figures 1,2). However, the link between the extent of the high and low nutrient water masses and circulation is indirect. It is possible that despite changes in circulation, a core 
site is bathed by the same water mass and this circulation change is not reflected in the nutrient status at this core site. Similarly, if the change in circulation persists for only a short period of time, the chemical properties of the deep water might not fully reflect the changes for several hundred years.

Here we present time-series of the oxygen isotopic composition of benthic foraminifera from the Florida Straits which we believe to be sensitive to changes in the upper branch of the AMOC, and the carbon isotopic composition of benthic foraminifera from the same region which can be used to reconstruct the nutrient concentration of intermediate waters. We use these records, together with existing reconstructions from other sites, to argue that if any reductions in the AMOC accompanied the two Heinrich Events that occurred during full glacial conditions $(\mathrm{H} 2, \mathrm{H} 3)$, they were of a much smaller magnitude and/or shorter duration than the reductions occurring during $\mathrm{H} 1$ and the Younger Dryas.

\section{Expression of Heinrich Stadials 1, 2 and 3 in the Florida Straits}

As it flows through the Florida Straits, the strength of the Florida Current reflects both the western limb of wind driven subtropical gyre and the warm surface waters that cross the equator and travel to the North Atlantic as part of the upper branch of the large scale overturning circulation associated with deep water formation. Any change in either this large scale overturning or wind driven gyre circulation can change the strength of this current. To first order, this current is in geostrophic balance so the vertical shear in the flow is proportional to the horizontal density gradient across the Straits. The density gradient at times in the past can be inferred from the oxygen isotopic composition of the calcite tests of benthic foraminifera from sediment cores on both sides of the current. The oxygen isotope ratio reflects both the 
temperature and oxygen isotopic composition (related to salinity) of the seawater in which it forms, and is therefore related to seawater density. Using this approach we have shown that the cross strait gradient was reduced during both the Last Glacial Maximum ${ }^{7}$ and the Younger Dryas $^{21}$. The reduced gradient can be explained by a reduction in the strength of the AMOC during the Last Glacial Maximum and Younger Dryas relative to the modern state, consistent with inferences based on other paleoceanographic studies using different methods.

While it is not possible to exclude the possibility that a reduced cross strait gradient reflected a reduced wind driven flow or a more barotropic Florida current, we do show that the link among AMOC strength, Florida Current strength and cross strait density gradient holds in a previously published model experiment (Supplemental Figure 5). In this model experiment, an AMOC reduction of $\sim 11 \mathrm{~Sv}$ was induced in CCSM by freshwater input into the subpolar North Atlantic under LGM conditions ${ }^{24}$. This AMOC reduction was accompanied by a reduction in Florida Straits transport of $\sim 10 \mathrm{~Sv}$, and a reduction in the cross straits density gradient at all depths below $300 \mathrm{~m}$. Details on the model experiment can be found in the Methods Section. In this paper we show isotopic data from two cores on either side of the Florida Straits (KNR166-2-26JPC, $24^{\circ} 19.61^{\prime} \mathrm{N}, 83^{\circ} 15.14^{\prime} \mathrm{W}, 546 \mathrm{~m}, \mathrm{KNR} 166-2-73 \mathrm{GGC}, 23^{\circ} 44.73^{\prime} \mathrm{N}, 7^{\circ}$ 25.78'S, 542 m, Figure 1). Details on the methods including age model development and isotopic measurements can be found in the Methods Section. The core on the Florida Margin extends through $36 \mathrm{kyr}$ before present, has high sedimentation rates (15-35 $\left.\mathrm{cm} \mathrm{kyr}^{-1}\right)$ during Marine Isotope Stages 2 and 3, and should be able to resolve changes associated with Heinrich Events during this interval. This core shows prominent excursions towards lower $\delta^{18} \mathrm{O}$ values (warmer or less saline, less dense waters) during the Younger Dryas and around the time the most recent Heinrich Event (Heinrich Stadial 1, HS1) (Figure 2a). The Younger Dryas excursion 
144 is associated with a reduction in cross strait $\delta^{18} \mathrm{O}$ gradient as inferred from three sediment cores

145 on each side of the Straits ( ref $^{21}$ ). Due to the low sedimentation rates between 13-20 kyr on the

146 Bahamas side of the straits, we have no direct evidence that the HS1 excursion was similarly

147 associated with a reduction in the cross strait density gradient. However, by analogy to the YD

148 excursion, such a reduction certainly seems plausible.

149 More generally, many general circulation models show mid-depth warming in the

150 subtropical North Atlantic when the AMOC is weakened in water hosing experiments in which

151 extra freshwater forcing is distributed over the northern North Atlantic. ${ }^{22}$ The warming is often

152 particularly apparent along the western margin of the subtropical North Atlantic ${ }^{23,24}$. As an

153 example, we show the mid-depth temperature anomaly from the model experiment with the 11

154 Sv freshwater-induced AMOC reduction described above (Figure 3). There is a positive mid-

155 depth temperature anomaly associated with the AMOC weakening along the entire western

156 margin of the basin. The mechanisms for this western margin warming are likely multiple and

157 linked, involving the dynamic adjustment of the density structure in association with the

158 circulation change, decreased heat transport out of the subtropics into the mid-latitude North

159 Atlantic, and a decreased contribution of the relatively cooler and fresher intermediate waters

160 from the South Atlantic..$^{24,25}$ In light of the results from these models, the negative excursion in

161 benthic foraminiferal $\delta^{18} \mathrm{O}$ along the Florida Margin, even in the absence of information about

162 the cross-strait density gradient, supports the scenario of an AMOC reduction during HS1. In the

163 model study shown in Figure 3, an AMOC reduction of $11 \mathrm{~Sv}$ was associated with an increase in

164 temperature at $550 \mathrm{~m}$ water depth along the South Forida Margin of $1.8^{\circ} \mathrm{C}$, which all else being

165 equal would correspond to a $\delta^{18} \mathrm{O}$ change in benthic foraminifera at this site of about $-0.5 \%$, the

166 same magnitude that is observed for HS1. There was only a small $(<0.1 \mathrm{psu})$ salinity anomaly at 
this location associated with the weakened AMOC. Regardless of the dominant process, an interpretation of the excursion towards lower $\delta^{18} \mathrm{O}$ at the Florida Margin as reflecting a reduced AMOC is consistent with the multiple lines of evidence for such a reduction during HS1 (ref. $\left.{ }^{11,12}\right)$.

In contrast, there is no indication of a significant change in cross-strait $\delta^{18} \mathrm{O}$ for the stadials associated with Heinrich events 2 and 3 (HS2, HS3). However the resolution of the Bahamas core may be insufficient to capture a short-lived reduction in the cross-strait gradient. But we do not see excursions towards lower benthic $\delta^{18} \mathrm{O}$ values similar in magnitude to that observed for the Younger Dryas and HS1 in the much higher resolution Florida core for HS2 or HS3. It is possible that competing processes (e.g. water mass property changes of the opposite sign which exactly matched in magnitude the changes associated with the flattening of isopycnals across the Florida Current, or a strengthening of the wind driven flow compensating a weakening of the AMOC) lead to a very muted or non-existent change in $\delta^{18} \mathrm{O}$ at this site, despite significant changes in the AMOC. However, it seems more reasonable to conclude, especially in light of the lack of compelling evidence for changes in the properties or extent of the deep Atlantic water masses during these Heinrich Stadials, that any changes in the AMOC in response to these two Heinrich Events were not comparable in size to the changes observed for the Younger Dryas or HS1. While the YD and HS1 are almost always associated with excursions in deep Atlantic $\delta^{13} \mathrm{C}$ (a proxy for nutrient content and water mass ventilation), similarly coherent excursions are not observed for HS2 and HS3 (Figure 2b, Supplemental Figure 2). While it is possible that the nutrient tracers would not fully respond to a very short duration change in ocean circulation, the upper ocean density structure, and thus the $\delta^{18} \mathrm{O}$ of foraminifera on the Florida Margin, would adjust very quickly to reflect a different flow state. 

changes. The sediments in this Heinrich layer are geochemically distinct from the others, it often shows up as a smaller peak in the concentration of ice rafted debris in sediment cores, and it is

193 limited to a smaller area in the North Atlantic than the other events ${ }^{26}$. It is certainly plausible that 194 a smaller volume of melt water, or the discharge of melt water into a different region within the

195 North Atlantic, could explain the lack of interruption of the AMOC. However, H2 appears

196 robust and geochemically similar to the events that do appear to be associated with circulation

197 changes $(\mathrm{H} 1, \mathrm{H} 4, \mathrm{H} 5)$. The lack of a large circulation change associated with $\mathrm{H} 2$ would

198 therefore require a different explanation.

\section{Response of ocean circulation to freshwater input sensitive to circulation state}

3) when the contrast between deep and intermediate $\delta^{13} \mathrm{C}$ values was not as extreme as during the

203 full glacial state (Figure $4 \mathrm{~d}$ ). The excursions in deepwater $\delta^{13} \mathrm{C}$ at the time of these earlier $\mathrm{H}$

204 events seem to reflect transitions from more weak stratification in the geochemical water mass

205 properties (modern type, associated with strong AMOC today), to the more strongly stratified

206 LGM water mass configuration which is associated with a weaker AMOC (Figure 5). The

207 Younger Dryas AMOC weakening is also thought to be melt water induced, and like HS4 and

208 HS5 seems to reflect a transition from a modern water mass configuration to one more similar to 209 the glacial state ${ }^{27}$.

We postulate that since the circulation was already in this more geochemically stratified,

211 weakened glacial state for the interval encompassing $\mathrm{H} 2$ and $\mathrm{H} 3$, the freshwater discharge

212 associated with these events was not able to weaken the AMOC further. This result apparently 
213 contradicts ocean general circulation model studies suggesting that a given freshwater input has a

214 stronger impact on AMOC strength in the glacial climate state than the modern state ${ }^{28-30}$.

215 Heinrich Event 1 also occurs during full glacial time, but the circulation event that is associated

216 with it seems particularly long and intense, lasting several thousand years, starting around the

217 time of the ice rafting event $\left(16.8 \mathrm{kyr} \mathrm{BP}\right.$, ref. $\left.{ }^{26}\right)$ and persisting well into the deglaciation until

218 about $14.7 \mathrm{kyr}$ BP (Figure 2) ${ }^{12}$. It is possible that the additional melt water entering the North

219 Atlantic as the Northern Hemisphere Ice Sheets began to decay helped to develop and sustain the

220 circulation change beyond the time of the Heinrich Event.

221 If the ice sheet surges only significantly impact the AMOC for some of the Hevents, this

222 has implications for the mechanisms responsible for the global expression of the $\mathrm{H}$ events. There

223 are some well resolved paleoclimate records in the Northern Hemisphere that suggest strong

224 changes in atmospheric circulation for all of the Heinrich stadials, including HS2 and HS3

225 (Figure 4). These include records of the Asian Monsoon from China ${ }^{1}$ and the ITCZ/monsoon 226 areas of the tropical Atlantic ${ }^{2,31}$ and ventilation in the Arabian $\mathrm{Sea}^{3}$. While changes in the heat

227 transport associated with the AMOC can change the position of the Atlantic ITCZ ${ }^{23}$, if there were 228 no, or only very subtle, changes in the AMOC over HS2 and HS3, a mechanism involving 229 atmospheric transmission is needed to explain the large signals for both the "circulation $\mathrm{H}$ 230 events" (H1, H4, H5, H6) and the H events that occur during peak glacial times (H2, H3). More 231 generally, cooling and increased land or sea ice cover in North Atlantic has also been shown to 232 cause shifts in the ITCZ ${ }^{32,33}$, providing a potential mechanism for ITCZ changes not directly 233 linked to the AMOC. Shifts in the Northern Hemisphere planetary wave patterns in response to 234 either North Atlantic sea ice extent or changes in ice sheet height ${ }^{34}$ might also provide a link 
235 between the $\mathrm{H}$ events in the North Atlantic and these lower latitude indicators of atmospheric

236 change.

\section{Methods}

Core KNR166-2-26JPC was taken from a water depth of $546 \mathrm{~m}$ on the Florida Margin and KNR166-2-73GGC was from a water depth of $542 \mathrm{~m}$ in the Santaren Channel (Bahamas). The age models for both cores were developed by linear interpolation between radiocarbon dates converted to calendar years using Calib 6.0 and the MARINE09 calibration data $\operatorname{set}^{35}$. In addition to the radiocarbon dates, the ages of Marine Isotope Stage $3-4$ and 4 - 5 boundaries were used to refine the age model for KNR166-2-73GGC (Supplemental Table 1). For

245 KNR162-2-26JPC the out of sequence dates between 344 and $408 \mathrm{~cm}$ were not used in the age model as was discussed in a previous publication on the deglacial portion of this core ${ }^{21}$. In

247 addition we do not use the date at $1032.25 \mathrm{~cm}$ depth due to the large error in the radiocarbon 248 measurement or the out of sequence date at $1088.25 \mathrm{~cm}$.

For core KNR166-2-26JPC both small single species groups (up to 4 individuals) and individuals of Planulina ariminensis, Cibicidoides pachyderma and Cibicidoides mollis from the 251 size fraction $>250 \mu \mathrm{m}$ were analyzed for oxygen and carbon isotopes. Isotope measurements 252 were made on a GV Instruments Optima with Multiprep at the Lamont-Doherty Earth 253 Observatory and a Finnigan MAT253 with Kiel carbonate preparation device at the Georgia 254 Institute of Technology. Values were calibrated using NBS-19 and NBS-18, and in all labs 255 internal precision met or exceeded $0.08 \%$ ( 1 sigma s.d. of replicate analyses of NBS-19 or in 256 house standards). We then averaged the $\delta^{18} \mathrm{O}$ values for all species at each depth interval, with an average of 5 individuals contributing to the average value at each depth. A small number of 
258 measurements show very low $\delta^{18} \mathrm{O}$ values, and presumably represent individuals that were transported down slope from shallower water depths. The values that were greater than two 260 standard deviations away from a robust loess smoothed version of the record were flagged (4\% 261 of the data) and not included in the average $\delta^{18} \mathrm{O}$ calculated for each depth (Supplemental Figure 262 4). The average value for each depth (outliers removed as described above) and the robust loess smooth are shown in Figure 2a. For the carbon isotope data shown in Figure 2b and Figure 4d, 264 only the data from $P$. ariminensis are averaged at each depth, as the $\delta^{13} \mathrm{C}$ values of the other species are consistently lower suggesting a phytodetritus effect at this location (Supplemental

266 Figure 4). Most data from the portion of the core younger than 15,000 ka BP was previously 267 published $^{21}$.

269 size fraction $>250 \mu \mathrm{m}$ were analyzed for oxygen and carbon isotopes. Isotope measurements 270 were made on a Finnigan MAT253 with Kiel carbonate preparation device at Georgia Institute of 271 Technology. We averaged the $\delta^{18} \mathrm{O}$ values for all species at each depth interval, with between 12723 individuals contributing to the average value at each depth. For the $\delta^{13} \mathrm{C}$ record shown in 273 Figure 3d, only values from C. pachyderma are averaged, since analyses for this species were 274 available for the entire length of the record. Where both species are analyzed in the Holocene 275 portion of the record, the $\delta^{13} \mathrm{C}$ of $C$. pachyderma is about $0.2 \%$ lower than $P$. ariminensis. The age model for the N. pachyderma $\delta^{18} \mathrm{O}$ record for MD95-2024P $\mathrm{P}^{36}$ (Figure 4a) was constructed by correlating the detrital layers in this core to the dates of the Heinrich Stadials in 278 the Hulu Cave oxygen isotope record ${ }^{1}$. The original age model for this core was determined in a 279 similar manner by correlating the detrital layers to the cold stadials in the Greenland ice core 
280 record $^{37}$. All other data sets plotted in Figure 4 are shown on their original published age

281 models.

The water hosing experiment shown in Figure $3 \mathrm{~b}$ was performed using the Community

283 Climate System Model, version 3.0, a fully coupled ocean-atmosphere global circulation model 284 developed at NCAR. The model experiment was initialized at year 400 of a control run under

285 LGM climate boundary conditions. Extra freshwater forcing of $0.25 \mathrm{~Sv}$ was uniformly

286 distributed over the subpolar North Atlantic $\left(50^{\circ}-70^{\circ} \mathrm{N}\right)$ for the $100 \mathrm{yr}$ duration of the

287 experiment. The maximum overturning weakens from $17 \mathrm{~Sv}$ in the LGM control run to $6 \mathrm{~Sv}$ in 288 the last 30 years of the experiment. The Florida Straits transport is well simulated in this model 289 and weakens from $33 \mathrm{~Sv}$ in the control run to $23 \mathrm{~Sv}$ in the experiment. This weakening is 290 accompanied by a decrease in the density gradient across the Florida Straits as all depths below $291300 \mathrm{~m}$ (Supplemental Figure 5). Further details on the model and experiment can be found in the 292 original publication ${ }^{24}$.

293 Data

294 All radiocarbon dates and isotope data reported in this study are archived at World Data 295 Center-A for Paleoclimatology located at the U.S. National Oceanic and Atmospheric 296 Administration (NOAA) National Climatic Data Center (NCDC) Paleoclimatology Program, 297 Boulder, Colorado. 


\section{References}

1 Wang, Y. J. et al. A high-resolution absolute-dated Late Pleistocene monsoon record from Hulu Cave, China. Science 294, 2345-2348 (2001).

2 Mulitza, S. et al. Sahel megadroughts triggered by glacial slowdowns of Atlantic meridional overturning. Paleoceanography 23, PA4206, doi:Doi 10.1029/2008pa001637 (2008).

3 Schulz, H., von Rad, U. \& Erlenkeuser, H. Correlation between Arabian Sea and Greenland climate oscillations of the past 110,000 years. Nature 393, 54-57 (1998).

4 Blunier, T. \& Brook, E. J. Timing of millennial-scale climate change in Antarctica and Greenland during the last glacial period. Science 291, 109-112 (2001).

5 Lynch-Stieglitz, J. et al. Atlantic meridional overturning circulation during the Last Glacial Maximum. Science 316, 66-69 (2007).

6 Lynch-Stieglitz, J. et al. Meridional overturning circulation in the South Atlantic at the last glacial maximum. Geochem Geophy Geosy 7, Q10N03, doi:10.1029/2005GC001226 (2006).

7 Lynch-Stieglitz, J., Curry, W. B. \& Slowey, N. Weaker Gulf Stream in the Florida Straits during the Last Glacial Maximum. Nature 402, 644-648 (1999).

8 Hesse, T., Butzin, M., Bickert, T. \& Lohmann, G. A model-data comparison of delta C-13 in the glacial Atlantic Ocean. Paleoceanography 26, doi:10.1029/2010pa002085 (2011).

9 Lippold, J. et al. Strength and geometry of the glacial Atlantic Meridional Overturning Circulation. Nature Geoscience 5, 813-816, doi:Doi 10.1038/Ngeo1608 (2012).

10 Rahmstorf, S. Ocean circulation and climate during the past 120,000 years. Nature 419, 207-214 (2002).

11 Sarnthein, M. et al. Changes in East Atlantic Deep-Water Circulation Over the Last 30,000 Years - 8 Time Slice Reconstructions. Paleoceanography 9, 209-267 (1994).

12 McManus, J. F., Francois, R., Gherardi, J. M., Keigwin, L. D. \& Brown-Leger, S. Collapse and rapid resumption of Atlantic meridional circulation linked to deglacial climate changes. Nature 428, 834-837 (2004).

13 Lippold, J. et al. Does sedimentary (231) $\mathrm{Pa} /(230) \mathrm{Th}$ from the Bermuda Rise monitor past Atlantic Meridional Overturning Circulation? Geophysical Research Letters 36, doi:10.1029/2009GL038068 (2009).

14 Boyle, E. A. Is ocean thermohaline circulation linked to abrupt stadial/interstadial transitions? Quaternary Science Reviews 19, 255-272 (2000).

15 Zahn, R. et al. Thermohaline instability in the North Atlantic during meltwater events: Stable isotope and ice-rafted detritus records from core SO75-26KL, Portuguese Margin. Paleoceanography 12, 696-710 (1997).

16 Peck, V. L., Hall, I. R., Zahn, R. \& Scourse, J. D. Progressive reduction in NE Atlantic intermediate water ventilation prior to Heinrich events: Response to NW European ice sheet instabilities? Geochem Geophy Geosy 8, -, doi:10.1029/2006gc001321 (2007).

17 Oppo, D. W. \& Lehman, S. J. Suborbital Timescale Variability of North-Atlantic Deep-Water During the Past 200,000 Years. Paleoceanography 10, 901-910 (1995).

18 van Kreveld, S. et al. Potential links between surging ice sheets, circulation changes, and the DansgaardOeschger cycles in the Irminger Sea, 60-18 kyr. Paleoceanography 15, 425-442 (2000).

19 Voelker, A. H. L. et al. Mediterranean outflow strengthening during northern hemisphere coolings: A salt source for the glacial Atlantic? Earth and Planetary Science Letters 245, 39-55, doi:Doi 10.1016/J.Eps1.2006.03.014 (2006).

20 Curry, W. B., Marchitto, T. M., McManus, J. F., Oppo, D. W. \& Laarkamp, K. L. in Mechanisms of Global Climate Change at Millennial Time Scales Vol. 112 Geophysical Monograph (eds PU Clark, RS Webb, \& LD Keigwin) 59-76 (American Geophysical Union, 1999).

21 Lynch-Stieglitz, J., Schmidt, M. W. \& Curry, W. B. Evidence from the Florida Straits for Younger Dryas ocean circulation changes. Paleoceanography 26, doi:10.1029/2010PA002032 (2011).

22 Stouffer, R. J. et al. Investigating the causes of the response of the thermohaline circulation to past and future climate changes. Journal of Climate 19, 1365-1387, doi:Doi 10.1175/Jcli3689.1 (2006).

23 Zhang, R. \& Delworth, T. L. Simulated tropical response to a substantial weakening of the Atlantic thermohaline circulation. Journal of Climate 18, 1853-1860 (2005). 
Schmidt, M. W. et al. Impact of abrupt deglacial climate change on tropical Atlantic subsurface temperatures. Proceedings of the National Academy of Sciences of the United States of America 109, 14348-14352, doi:Doi 10.1073/Pnas.1207806109 (2012).

25 Chang, P. et al. Oceanic link between abrupt changes in the North Atlantic Ocean and the African monsoon. Nature Geoscience 1, 444-448, doi:Doi 10.1038/Ngeo218 (2008).

26 Hemming, S. R. Heinrich events: Massive late pleistocene detritus layers of the North Atlantic and their global climate imprint. Reviews of Geophysics 42, -, doi:10.1029/2003rg000128 (2004).

27 Keigwin, L. D. Radiocarbon and stable isotope constraints on Last Glacial Maximum and Younger Dryas ventilation in the western North Atlantic. Paleoceanography 19, doi:10.1029/2004PA001029 (2004). Bitz, C. M., Chiang, J. C. H., Cheng, W. \& Barsugli, J. J. Rates of thermohaline recovery from freshwater pulses in modern, Last Glacial Maximum, and greenhouse warming climates. Geophysical Research Letters 34, -, doi:10.1029/2006GL029237 (2007). Weber, S. L. \& Drijfhout, S. S. Stability of the Atlantic meridional overturning circulation in the last glacial maximum climate. Geophysical Research Letters 34, -, doi:10.1029/2007g1031437 (2007). Condions in an OAGCM. Impact of Freshwater Release in the North Atlantic under Different Climate Conditions in an OAGCM. Journal of Climate 22, 6377-6403, doi:Doi 10.1175/2009jcli3028.1 (2009). Arz, H. W., Patzold, J. \& Wefer, G. Correlated millennial-scale changes in surface hydrography and terrigenous sediment yield inferred from last-glacial marine deposits off northeastern Brazil. Quaternary Research 50, 157-166 (1998). Broccoli, A. J., Dahl, K. A. \& Stouffer, R. J. Response of the ITCZ to Northern Hemisphere cooling. Geophysical Research Letters 33, -, doi:10.1029/2005GL024546 (2006). Chiang, J. C. H., Biasutti, M. \& Battisti, D. S. Sensitivity of the Atlantic Intertropical Convergence Zone to Last Glacial Maximum boundary conditions. Paleoceanography 18, -, doi:10.1029/2003PA000916 (2003). Wunsch, C. Abrupt climate change: An alternative view. Quaternary Research 65, 191-203 (2006). Reimer, P. J. et al. Intca109 and Marine09 Radiocarbon Age Calibration Curves, 0-50,000 Years Cal Bp. Radiocarbon 51, 1111-1150 (2009). Hillaire-Marcel, C. \& Bilodeau, G. Instabilities in the Labrador Sea water mass structure during the last climatic cycle. Can J Earth Sci 37, 795-809 (2000). Stoner, J. S., Channell, J. E. T., Hillaire-Marcel, C. \& Kissel, C. Geomagnetic paleointensity and environmental record from Labrador Sea core MD95-2024: global marine sediment and ice core chronostratigraphy for the last 110 kyr. Earth and Planetary Science Letters 183, 161-177 (2000). Conkright, M. E. et al. World Ocean Database 2001. Vol. 1 (U.S. Government Printing Office, 2002). Hodell, D. A., Channell, J. E. T., Curtis, J. H., Romero, O. E. \& Rohl, U. Onset of "Hudson Strait" Heinrich events in the eastern North Atlantic at the end of the middle Pleistocene transition (similar to $640 \mathrm{ka}$ )? Paleoceanography 23, doi:10.1029/2008PA001591 (2008).

40 Hodell, D. A., Evans, H. F., Channell, J. E. T. \& Curtis, J. H. Phase relationships of North Atlantic icerafted debris and surface-deep climate proxies during the last glacial period. Quaternary Science Reviews 29, 3875-3886, doi:10.1016/J.Quascirev.2010.09.006 (2010). Shackleton, N. J., Hall, M. A. \& Vincent, E. Phase relationships between millennial-scale events 64,00024,000 years ago. Paleoceanography 15, 565-569 (2000).

2 Skinner, L. C., Elderfield, H. \& Hall, M. in Ocean Circulation: Mechanisms and Impacts Geophysical Monograph Series (eds A. Schmittner, J. Chiang, \& S. Hemming) 197-208 (American Geophysical Union, 2007). Tjallingii, R. et al. Coherent high- and low-latitude control of the northwest African hydrological balance. Nature Geoscience 1, 670-675, doi:Doi 10.1038/Ngeo289 (2008). Zarriess, M. \& Mackensen, A. Testing the impact of seasonal phytodetritus deposition on delta(13)C of epibenthic foraminifer Cibicidoides wuellerstorfi: A 31,000 year high-resolution record from the northwest African continental slope. Paleoceanography 26, doi:10.1029/2010pa001944 (2011). Zarriess, M. Primary Productivity and Ocean Circulation Changes on orbital and millennial Timescales off Northwest Africa during the Last Glacial/Interglacial Cycle: Evidence from benthic foraminiferal Assemblages, stable carbon and oxygen isotopes and $\mathrm{Mg} / \mathrm{Ca}$ Paleothermometry Ph.D. thesis, Universitat Bremen, (2010).

6 Garcia, H. E. et al. World Ocean Atlas 2009, Volume 4: Nutrients (phosphate, nitrate, silicate). (U.S. Government Printing Office, 2010).

7 Curry, W. B. \& Oppo, D. W. Glacial water mass geometry and the distribution of $\mathrm{d}^{13} \mathrm{C}$ of $\mathrm{SCO}_{2}$ in the western Atlantic Ocean. Paleoceanography 20, PA1017, doi:10.1029/2004PA001021 (2005). 
413 Correspondence and requests for materials should be directed to Jean Lynch-Stieglitz

\section{Acknowledgments}

416 The authors acknowledge the US National Science Foundation (OCE-0096472, OCE-0648258

417 and OCE-1102743), a grant from the Comer Science and Education Foundation and a Rutt

418 Bridges Undergraduate Research Fellowship to L.G.H. for funding this work. PC acknowledges

419 the supports from the Natural Science Foundation of China (40921004 and 40930844). S.M. was

420 funded through the DFG Research Center/Cluster of Excellence "The Ocean in the Earth

421 System". We also thank Tiee-Yuh Chang for technical assistance.

422

\section{Competing Financial Interests}

424 The authors have no competing financial interest.

425

426 Contributions

427 J.L.S., W.B.C., M.W.S. and L.G.H. collected and analyzed the sedimentary materials from 428 KNR166-2, L.C.S. and S.M. contributed to the benthic carbon isotope compilation and P.C. and 429 R.Z. contributed model output. All authors contributed to the interpretation of the data and 430 model results and participated in the preparation of the manuscript. 

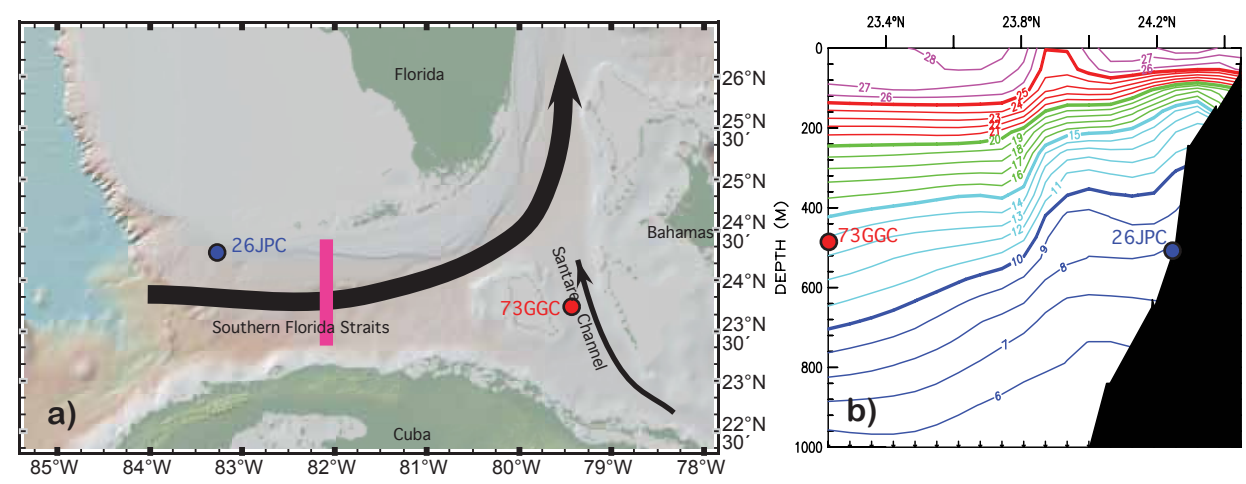

Fig. 1. Core Locations and Context a) Location of sediment cores for the data shown in Figure 2. The location of the temperature section shown in panel (b) is indicated with the pink line, and the approximate path of the Florida Current with the large black arrow. b) A Northsouth section of climatological temperature $\left({ }^{\circ} \mathrm{C}\right)$ across the Florida Straits at $82^{\circ} \mathrm{W}$, with the depth of the two sediment cores used to monitor the cross Straits density gradient indicated with circles ${ }^{38}$.

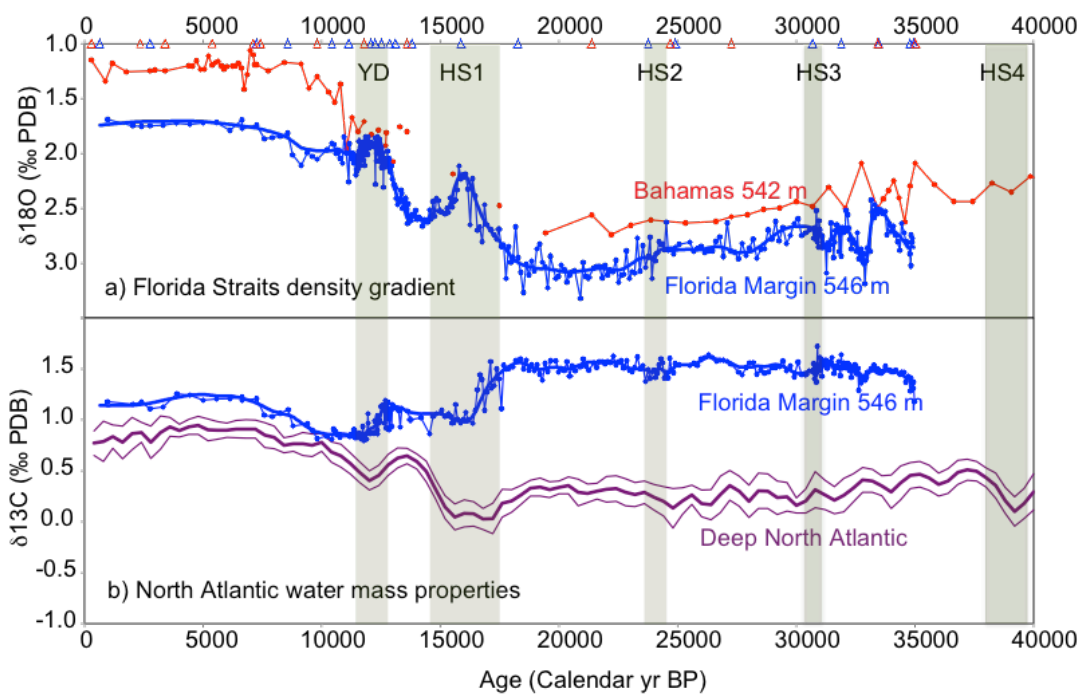

Fig. 2. Glacial and Deglacial Records a) Oxygen isotope ratio in benthic foraminifera from two cores on either side of the Florida Current (blue: KNR166-2-26JPC, red: KNR166-2-73GC, Locations shown on Figure 1). Depths of radiocarbon dates in these cores are indicated by triangles on the top axis. b) Carbon isotope ratios from the benthic foraminifera Planulina ariminensis from the same core on the Florida side of the Straits (blue: KNR166-2-26JPC, Location A on Figure 5), and average (800 year window) and +/- 2 standard error (purple) of eight high resolution Cibicidoides wuellerstorfi $\delta^{13} \mathrm{C}$ records from the deep Atlantic ${ }^{17,39-45}$. (Core Locations shown in Figure 5). 


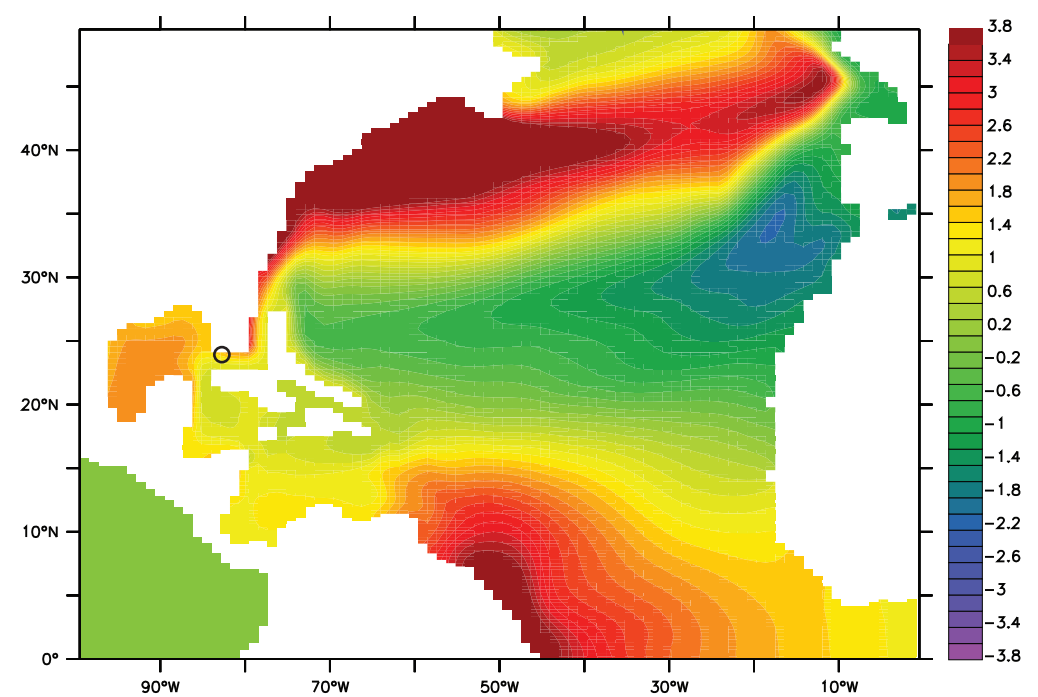

Fig. 3. Modelled Temperature Anomaly Temperature anomaly (K) at $579 \mathrm{~m}$ for water hosing experiment $(0.25 \mathrm{~Sv})$ with LGM boundary conditions in CCSM3 (11 Sv AMOC reduction) ${ }^{24}$. The location of KNR166-2-26JPC is indicated with a black circle. 


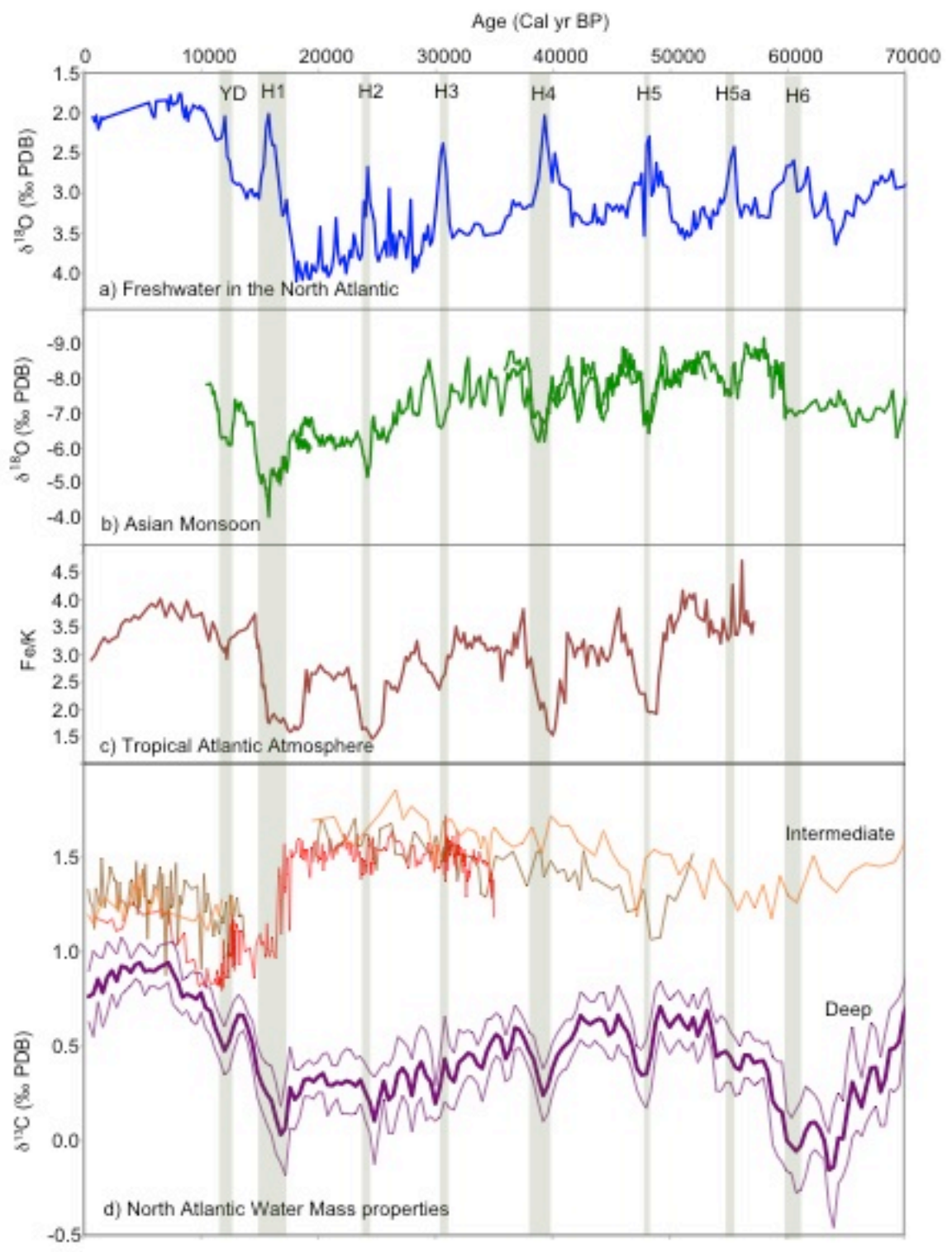

Fig. 4. Stage 3 Records a) Oxygen isotope ratio in the planktonic foraminifera Neogloboquadrina pachyderma ( $l$ ) from the western North Atlantic ${ }^{36}$ (Location E, Figure 5). Low values reflect presence of glacial melt water. b) Oxygen isotope ratio in cave deposits in China, reflecting changes in monsoon precipitation ${ }^{1}$. Green vertical bars extending through all of the plots indicate the timing of the Younger Dryas and Heinrich stadials from this record. c) The Fe/K ratio, an indicator of aridity in the West African Sahel (Location D, Figure 5) ${ }^{2}$. d) Carbon isotope ratios in benthic foraminifera from intermediate waters (red: $546 \mathrm{~m}$ Location A on Figure 5; orange: $542 \mathrm{~m}$ Location B on Figure 5) (this study) and (brown: $965 \mathrm{~m}$ Location C in Figure 5) ${ }^{20}$. Average (800 year window) and $+/-2$ standard error (purple) of seven high resolution Cibicidoides wuellerstorfi $\delta^{13} \mathrm{C}$ records from the deep Atlantic ${ }^{17,39-45}$. (Locations in Figure 5, Individual records in Supplemental Figure 2). 

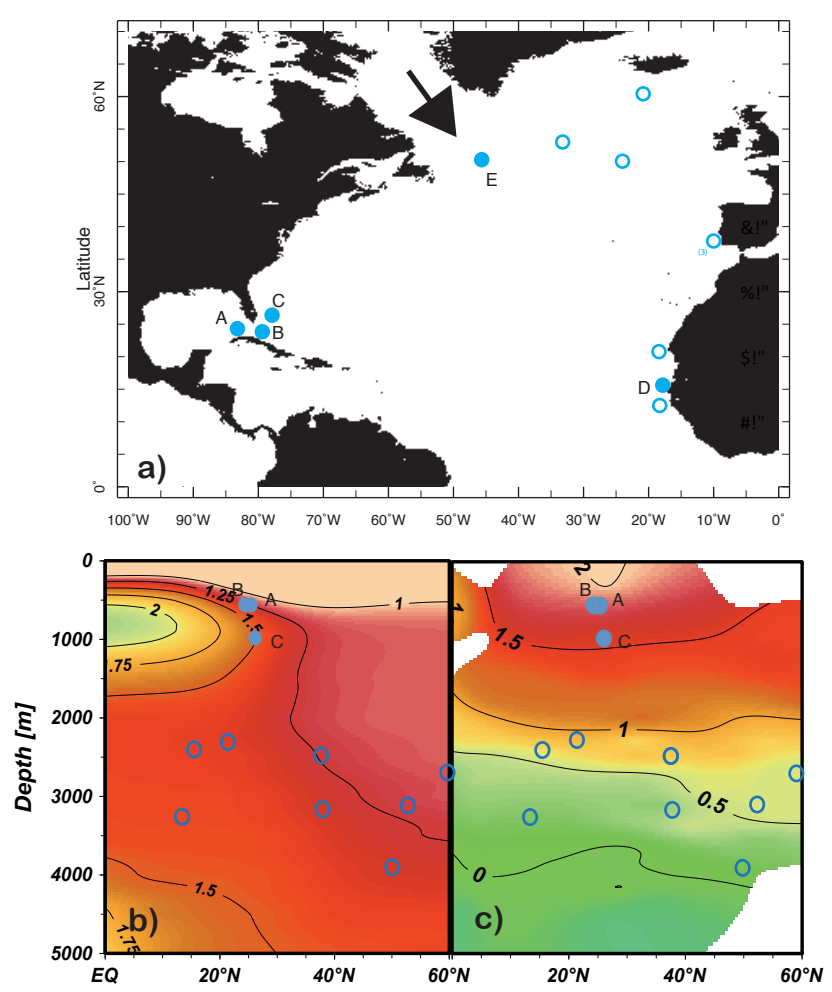

Fig. 5. Location of other Records a) Location of sediment cores for the data shown in Figures 2 and 3 (solid circles) and that contributed towards the deep North Atlantic $\delta^{13} \mathrm{C}$ averages (open circles). The source of the Heinrich ice surges from the Hudson Straits is marked with an arrow. b) Modern $\mathrm{PO}_{4}\left(\mu \mathrm{mol} \mathrm{kg}{ }^{-1}\right)$ distribution in the North Atlantic ${ }^{46}$ with location of sediment cores for the carbon isotope records shown in Figure 4 indicated with solid circles and those contributing towards the deep North Atlantic $\delta^{13} \mathrm{C}$ averages with open circles. c) Glacial $\delta^{13} \mathrm{C}$ (\% PDB) distribution in the North Atlantic ${ }^{47}$. 